\title{
Using GLP as Partial Replacement in Cement Mortars
}

\author{
Ahmed El-Tair ${ }^{1}$, Passant Youssef $^{1 *}$, and Amr El-Nemr ${ }^{1}$ \\ ${ }^{1}$ Civil Engineering Department, German University in Cairo, Cairo, Egypt
}

\begin{abstract}
For the last decade, recycled construction wastes were promoted to be reused in concrete manufacture process to achieve sustainability of structures. Recently, crushed glass has been investigated many researchers [1-9] as a partially replacement for coarse and fine aggregates, finally; cement. This study investigated the influence of both the mechanical behaviour and microstructure of cement mortar when partially replaced by powder glass. Here in, six mixes were design for six percentages of replacement; considered incrementally, each $5 \%(0 \%, 5 \%, 10 \%, 15 \%$, $20 \%$, and $25 \%$ ) of cement weight. 36 mortar cubes and 18 prisms were cast and cured for 28 days. Then after, the specimens were tested in compression and indirect splitting tensile strength to determine their influence on mechanical properties. In addition, scanning electron microscope as well X-ray diffraction was used to examine their microstructure cement. The results showed that $20.5 \%$ increase in compressive strength at 7 days while at 28 days, the compressive strength increases insignificantly by value of $0.3 \%$ when using 5\% GLP replacement. In addition, $46.9 \%$ increase was achieved in flexural strength at 28 days. Furthermore, the SEM micrographs observed some clear glass particles while the XRD clearly monitored the high count of silica and could not detect the calcium silicate that represents the amorphous part.
\end{abstract}

\section{Introduction}

For the last decade, recycled construction wastes were promoted to be reused in concrete manufacture process to achieve sustainability of structures. Recently, crushed glass has been investigated as partially replacement for coarse and fine aggregates, finally; cement. Different percentages of GLP replacement in cement mortars were countered in the last period. Most of the studies were carried out to judge the cement mortars properties at an early and late age [1-2]. The authors [3 - 4] believed that there is a significant increase in compressive strength for $20 \%$ percentages of GLP replacement or more by cement weight as well flexural strength [3]. Others proved that compressive strength increases with increase in percentage of GLP replacement up to $20 \%$; while, beyond $20 \%$ of GLP replacement, the strength decreases. Similar behaviour was deduced when testing the concrete for flexural strength [4].

\section{Research Significance}

The significance of this study is to investigate the influence on both the mechanical behaviour and microstructure of cement mortar when partially replaced by GLP using XRD diffraction and SEM. This was achieved through testing 36 mortar cubes and 18 prisms that represents different GLP replacement $(0 \%, 5 \%$, $10 \%, 15 \%, 20 \%$, and $25 \%$ ) after cast and curing for 28 days in compression and splitting tensile test. In addition, parts of these specimens were examined under scanning electron microscope as well as $\mathrm{X}$ ray diffraction. The results showed different approaches than those achieved in literature.

\section{Experimental Programs}

Table 1. Mixture Composition.

\begin{tabular}{|c|c|c|c|c|c|c|}
\hline $\begin{array}{c}\text { GLP Replacement } \\
\%\end{array}$ & $0 \%$ & $5 \%$ & $10 \%$ & $15 \%$ & $20 \%$ & $25 \%$ \\
\hline Cement (gm) & 1000 & 950 & 900 & 850 & 800 & 750 \\
\hline Glass powder (gm) & 0 & 50 & 100 & 150 & 200 & 250 \\
\hline Sand (gm) & \multicolumn{5}{|c|}{2000} \\
\hline Water (ml) & \multicolumn{5}{|c|}{400} \\
\hline S.P. (ml) & 4 \\
\hline
\end{tabular}

Table 1 shows the proportions weight of each cement mix. In this study, total of 6 mixes of cement pastes were designed to include different percentage of GLP replacement $(0,5 \%, 10 \%, 15 \%, 20 \%$ and $25 \%$ of cement weight) as shown in Table 1. Each mix composed of 6 cubes $50 \mathrm{~mm} \times 50 \mathrm{~mm} \times 50 \mathrm{~mm}$ in dimensions for testing compressive strength after 7 and 28 days, in addition, prisms $40 \mathrm{~mm}$ height $\mathrm{x} 40 \mathrm{~mm}$ width $\mathrm{x} 160 \mathrm{~mm}$ length for flexural strength test.

* Corresponding author: passant.ahmed $@$ guc.edu.eg 
The w/c ratio assigned was constant in all mixes by a value of 0.4 . A super-plasticizer admixture was added by value $0.4 \%$ of cement weight as well.

\subsection{Materials}

The materials used were as following; Ordinary Portland cement grade 42.5 its specific gravity was provided to be equal 3.1, in addition to, standard sand as well as potable water. Table 2 represents the chemical composition in percentage by weight for cement. The glass powder was obtained from the crushed glass plates while handling in Glass factory. The manufacturer provided us with crushed glass and using laboratory grinding machine, the glass was crushed to smaller pieces of size less than 300 $\mu \mathrm{m}$ (passing percentage by sieve $300 \mu \mathrm{m}$ ).

Table 2 - Properties of Portland cement (wt. \%)

\begin{tabular}{|c|c|c|c|c|c|}
\hline Element & $\mathbf{S i O}_{2}$ & $\mathbf{A l}_{2} \mathbf{O}_{3}$ & $\mathbf{F e}_{2} \mathbf{O}_{3}$ & $\mathbf{C a O}$ & $\mathbf{S O}_{3}$ \\
\hline Cement & 20.13 & 5.32 & 3.61 & 61.63 & 2.87 \\
\hline Element & $\mathbf{N a}_{2} \mathbf{O}$ & $\mathbf{K}_{2} \mathbf{O}$ & L.O.I & $\mathbf{M g O}$ & \\
\hline Cement & 0.37 & 0.13 & 1.96 & 2.39 & \\
\hline
\end{tabular}

Recycled glass powder of size less than $300 \mu \mathrm{m}$ was used in this investigation. Fig. 1 presents the glass powder used as replacement of cement in this study.

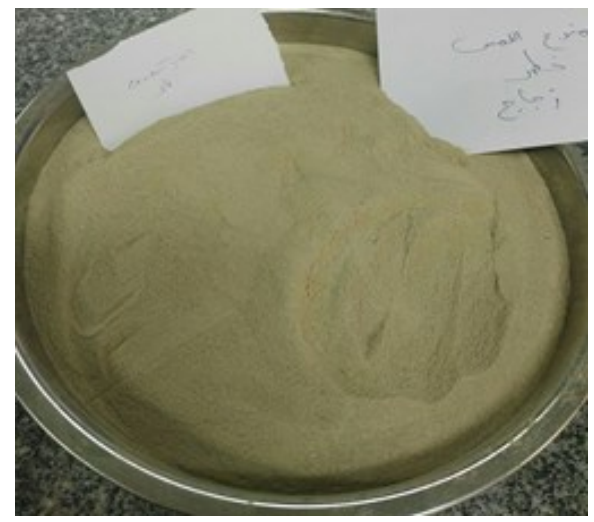

Fig. 1. Glass Powder used as replacement of cement

Potable water used from the water-supply network system, free from suspended solid and organic materials, which can affect the properties of the fresh and hardened concrete. The standard sand used in mortars is free of alkali-reactive materials to ensure producing durable composites.

Finally, water reducer [super-plasticizer] admixture up to $20 \%$, a substantial improvement in workability without increase water or risk in segregation was added. The admixtures showed no adverse effect on ultimate strengths.

Mixing procedure was occurred by mixing the solid materials together first; cement, sand and glass powder then adding water and super-plasticizer to the mix. The samples mix is carried out using ELE mixer machine as shown in Fig.2.

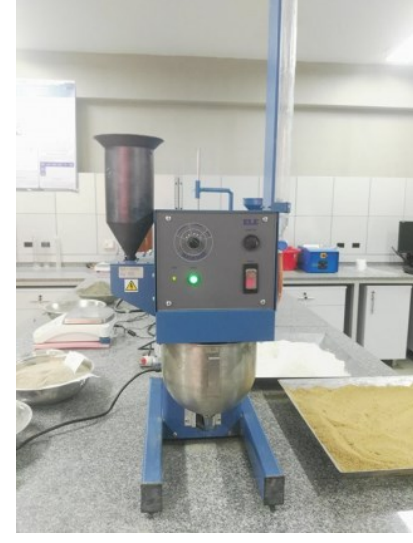

Fig. 2. ELE machine for mixing samples

\subsection{Specimens}

36 mortar plain cube specimens with dimensions $50 \mathrm{~mm}$ x $50 \mathrm{~mm}$ x $50 \mathrm{~mm}$ and 18 prisms cube specimens of height $40 \mathrm{~mm}$, width $40 \mathrm{~mm}$, and length $160 \mathrm{~mm}$ were constructed and cured for 28 days. The specimens were tested for compression and splitting tensile strength. Moreover, the specimens were examined using SEM micrographs and XRD to investigate the microstructure of cement mortar.

\subsection{Items of investigation}

The compressive strength test of the cement mortars was determined at 7 and 28 days of water curing as per ASTM C39 [5]. The test is carried out using ELE compressive machine shown in Fig. 3 at loading rate of $0.5 \mathrm{~N} / \mathrm{mm}^{2} / \mathrm{sec}$.

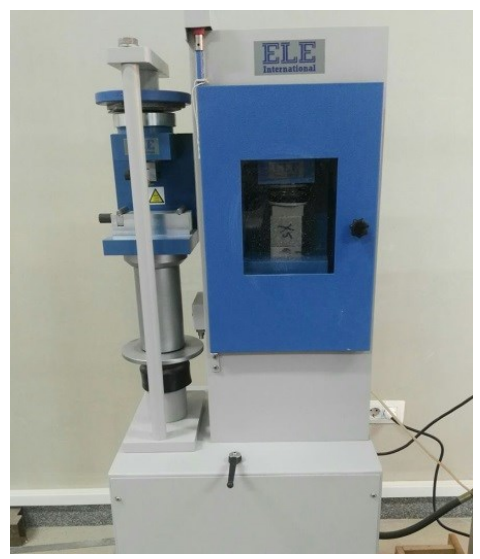

Fig. 3. ELE machine for compression tests

Flexural strength is a mechanical property for brittle material, defined as a material's ability to resist deformation under load. When an object formed of a single material subjected to bending, it experiences a range of stresses across its depth at the extreme chords. Most materials, before passing through compression failure criteria, fail under tensile stress. Disregarding the low ability of concrete to sustain tension stresses, the concrete flexural strength is considered to be the 
maximum tensile stress value that can be reached before the beam fails [6]. The test is determined at 28 days of water curing as per ASTM C78 [7]. The test is carried out using ELE flexural machine as shown in Fig.3 at loading rate of $0.06 \mathrm{~N} / \mathrm{mm}^{2} / \mathrm{sec}$. Fig. 4 shows the prism specimen under flexural loading for determining the tensile strength of mortar.

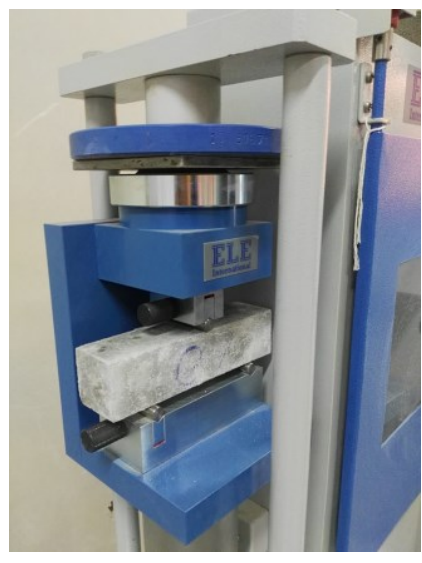

Fig. 4. ELE machine for flexure tests

\section{Experimental Results and Discussion}

\subsection{Consistency}

Flow table test according to ASTM standards C230-83 as shown in fig. 5 was investigated to determine consistency of fresh mortars. It is used primarily for assessing concrete that is too fluid (workable) to be measured using the slump test, because the concrete will not retain its shape when the cone is removed. The flowability percentage was calculated using the below equation;

$\%$ of flowability $=[$ (average diameter for flowable mortar -100$) / 100] * 100 \%$

It was found that by the increase of glass powder amount the mortar's flowability decreases. The percentage of flowability of cement mortars was equal to $80 \%, 78 \%$ and $77 \%$ by adding glass powder amount $0 \%$, $15 \%$ and $25 \%$ by cement weight respectively.
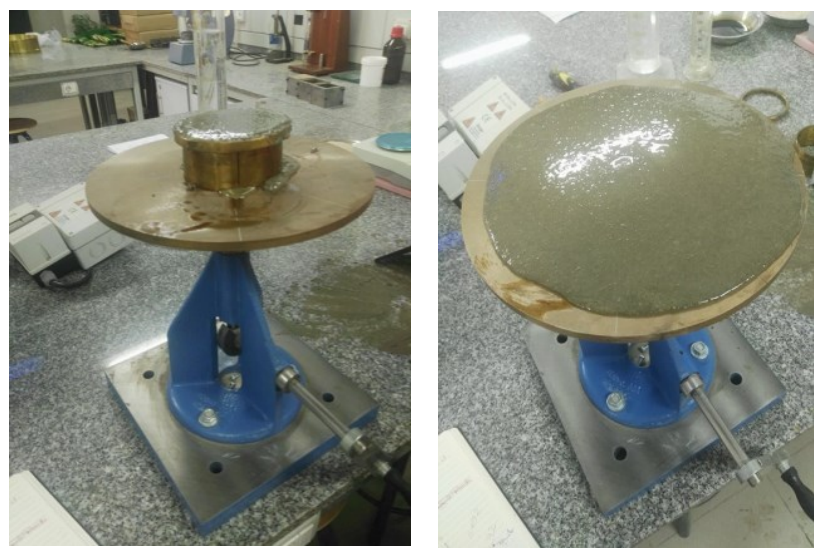

Fig.5. Flow table test

\subsection{Compressive strength}

Fig. 6 and 7; present the early (7 days) and late age (28 days) compressive strength for glass powder replacement $0 \%$ to $25 \%$ by cement weight. The results showed that the 7 days compressive strength obtained for the specimens with $5 \%, 10 \%$ and $15 \%$ GLP replacement by cement weight achieved higher compressive strength than that of the control specimen. Moreover, the maximum compressive strength was achieved at an optimum value of 5\% GLP replacement by cement weight after 7 days of water curing where compressive strength increased by $20.5 \%$ compared to control specimen and $0.3 \%$ after 28 days of water curing. It should be mentioned that when cement was replaced by weight $20 \%$ and $25 \%$ GLP; the compressive strengths were $4.2 \%$ and $12.6 \%$ lower than that of control sample after 7 days testing. Stresses values are shown in Table 3 and 4.

Table 3. 7 days compressive strength

\begin{tabular}{|c|c|c|c|c|}
\hline $\begin{array}{c}\text { Sampl } \\
\mathbf{e}\end{array}$ & $\begin{array}{c}\text { Dimensions } \\
\mathbf{( m )}\end{array}$ & $\begin{array}{c}\text { Area } \\
\mathbf{( m 2 )}\end{array}$ & $\begin{array}{c}\text { Volume } \\
\mathbf{( m 3 )}\end{array}$ & $\begin{array}{c}\text { Stress } \\
\mathbf{( M P a} \\
\mathbf{)}\end{array}$ \\
\hline $\mathrm{G} 0$ & $5 * 5$ & 25 & 125 & 22.6 \\
\hline G5 & $5 * 5$ & 25 & 125 & 27.2 \\
\hline G10 & $5 * 5$ & 25 & 125 & 24.7 \\
\hline G15 & $5 * 5$ & 25 & 125 & 24.4 \\
\hline G20 & $5 * 5$ & 25 & 125 & 21.6 \\
\hline G25 & $5 * 5$ & 25 & 125 & 19.8 \\
\hline
\end{tabular}




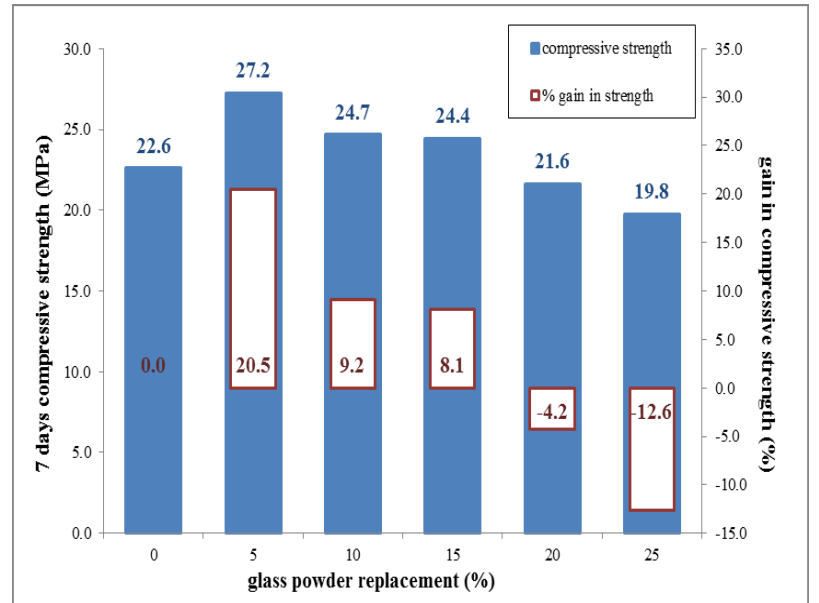

Fig.6. 7 days compressive strength for cement mortars

While at 28 days; the compressive strength were totally lower than that of control by $2.1 \%, 15.3 \%, 22.7 \%$ and $34.8 \%$ for GLP replacement $10 \%, 15 \%, 20 \%$ and $25 \%$, respectively, as shown in Figure 7 . This can be attributed to the pozzolanic reaction between silica in GLP and alkalis in cement, to form a dense mass resisting the stresses loaded. In addition to, the filling effect of voids by GLP in cement matrix. On the other hand, the reduction in strength when increasing GLP replacement more than $5 \%$ is attributed to the agglomeration occurred of the GLP powder which increase the micro voids in the cement matrix. This conclusion was in a good agreement with Subramani et al. [8] findings when investigated increasing the GLP replacement more than $5 \%$. On the other hand, Sharma [9] found that the key percentage was more than $10 \%$ of GLP replacement were more agglomeration occurred and consecutively, followed by reduction in compressive strength. Therefore, it was recommended by Kumar [10] to replace the GLP by fine aggregate not by cement with an ideal percentage value of $20 \%$.

Table 4. 28 days compressive strength

\begin{tabular}{|c|c|c|c|c|}
\hline Sample & $\begin{array}{c}\text { Dimensions } \\
(\mathbf{m})\end{array}$ & $\begin{array}{c}\text { Area } \\
(\mathbf{m} 2)\end{array}$ & $\begin{array}{c}\text { Volume } \\
(\mathbf{m} 3)\end{array}$ & $\begin{array}{c}\text { Stress } \\
\mathbf{( M P a})\end{array}$ \\
\hline $\mathrm{G} 0$ & $5 * 5$ & 25 & 125 & 33.9 \\
\hline $\mathrm{G} 5$ & $5 * 5$ & 25 & 125 & 34.0 \\
\hline G10 & $5 * 5$ & 25 & 125 & 33.2 \\
\hline G15 & $5 * 5$ & 25 & 125 & 28.7 \\
\hline G20 & $5 * 5$ & 25 & 125 & 26.2 \\
\hline G25 & $5 * 5$ & 25 & 125 & 22.1 \\
\hline
\end{tabular}

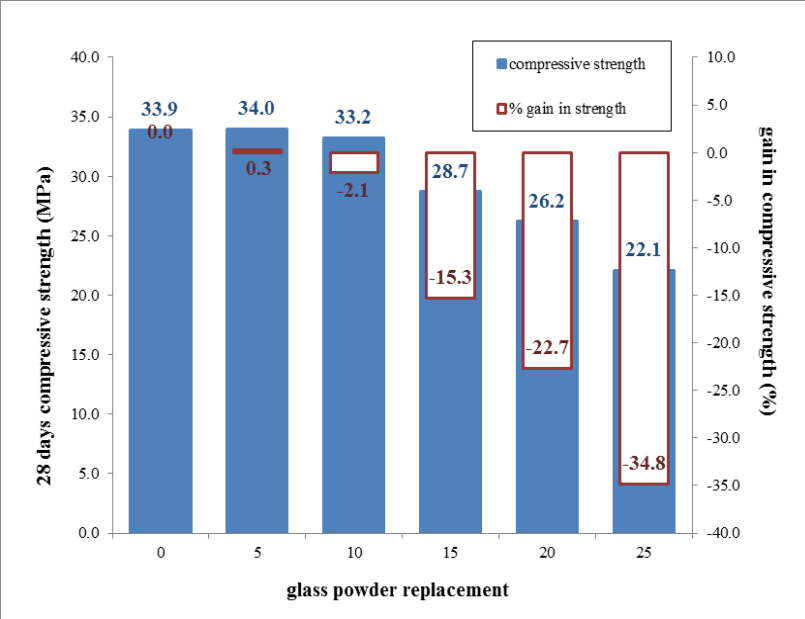

Fig.7. 28 days compressive strength for cement mortars

\subsection{Flexure Strength}

Fig. 8 and 9 show the flexural strength results of cement mortar of $0 \%$ to $25 \%$ GLP replacement after 28 days. The results observed that higher flexural strength were achieved than that of control specimen in all GLP replacement by $46.9,46.9,34.4,34.4$ and $31.3 \%$ respectively. The optimum percentage of glass powder replacement was $5 \%$ and $10 \%$ by cement weight after 28 days of water curing; compressive strength increased by $46.9 \%$; consequently the flexural strength increased by $34.4 \%$ for $15 \%$ and $20 \%$ glass powder replacement and $31.3 \%$ for $25 \%$ glass powder by cement weight. The same findings were confirmed by Shruthi el al. [11].

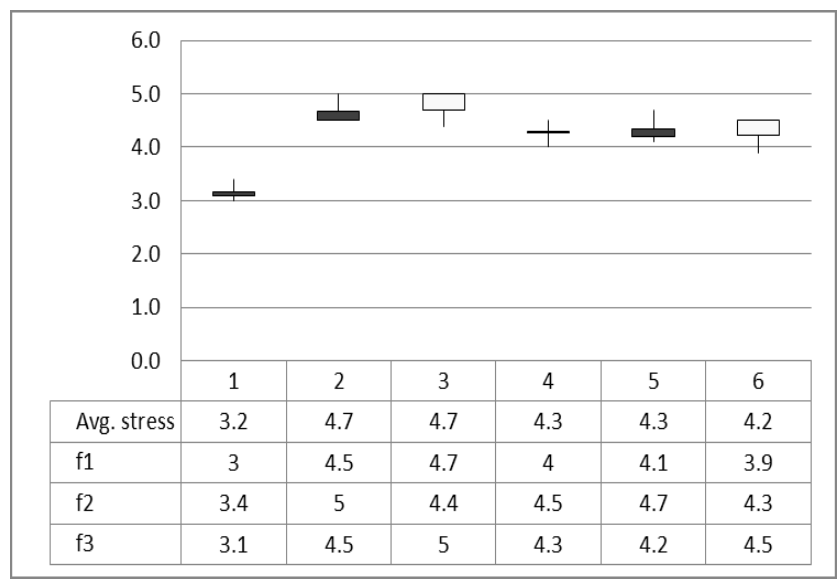

Fig.8. 28 days flexure strength for 3 prisms 


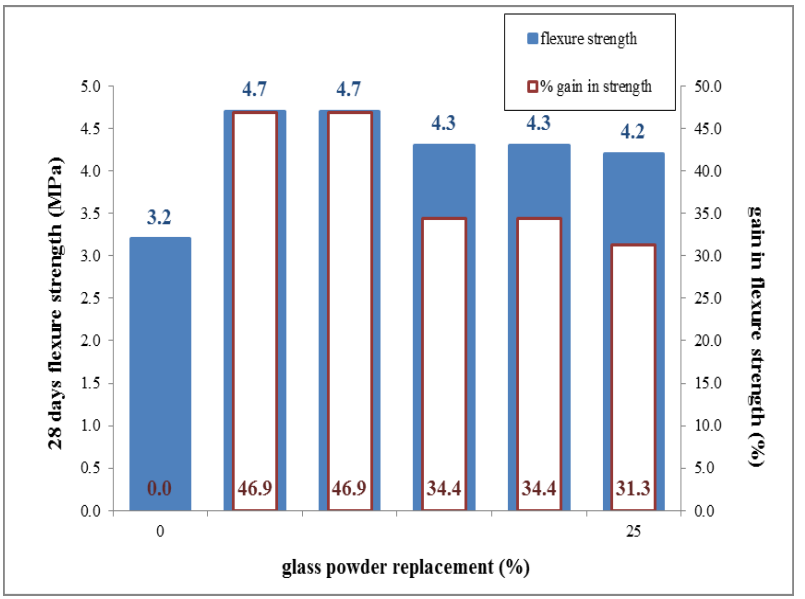

Fig.9. 28 days flexural strength for cement mortars

\subsection{Microstructure Analysis}

Scanning electron microscopy (SEM) and X-ray diffraction (XRD) were used to examine the nature of the hydrated binder and the binder-aggregate interfacial zones. Figure 10 and 11 show SEM micrograph of the control cement mortar ( $0 \%$ GLP replacement) and the mechanically optimized cement mortar which includes $5 \%$ of GLP replacement by cement weight, as discussed from the previous section (return to section 4.2 compressive strength). Micro cracks in the control specimen were observed by the SEM micrographs for cement mortars although 28 days of water curing. On the other hand, the optimum specimen, which contained 5\% GLP replacement by cement weight, showed a very dense matrix with less voids. The agglomeration of glass powder in the matrix is detected in the optimum specimen (5\% GLP replacement).

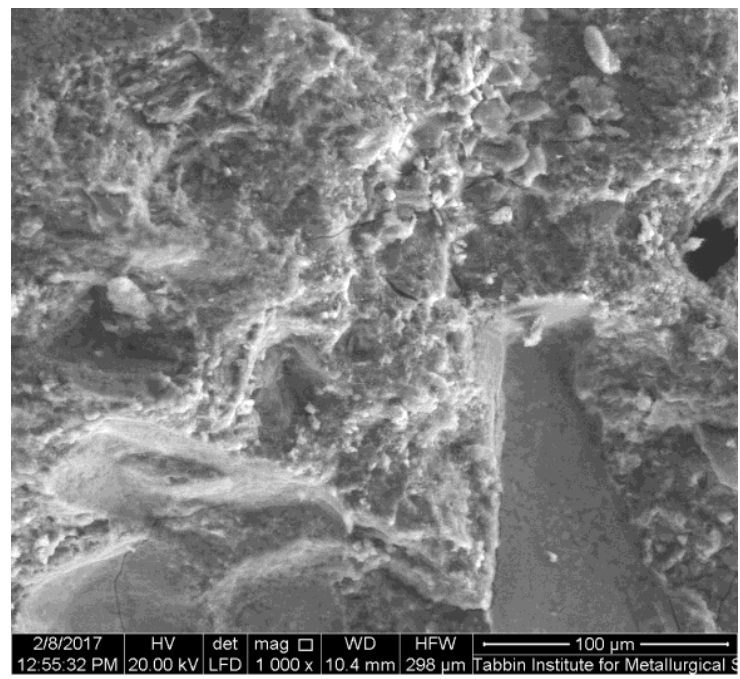

Fig.10. SEM micrograph of the control cement mortar $(0 \%$ glass powder replacement)

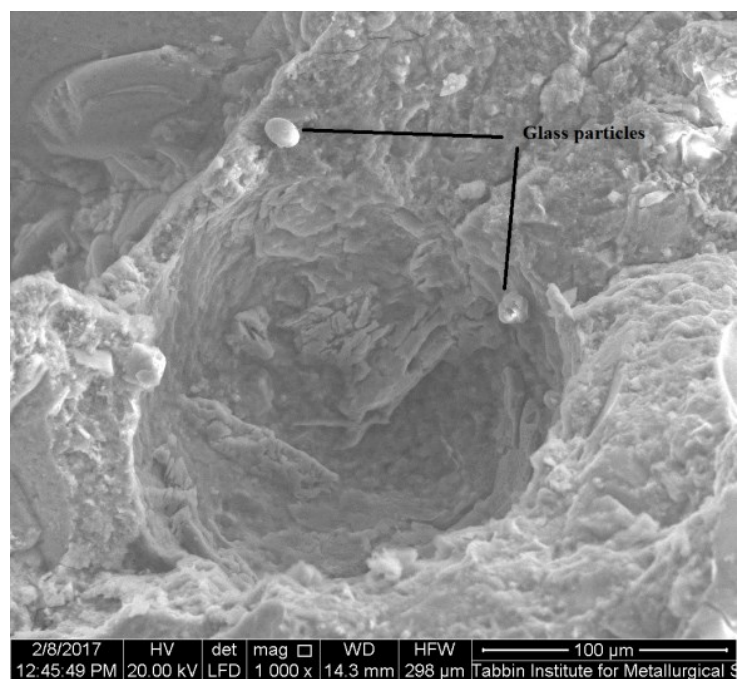

Fig.11. SEM micrograph of the optimum cement mortar contains $5 \%$ of glass powder replacement by cement weight

Fig. 12 shows the XRD diagram for 5\% GLP replacement by cement weight in mortar. The diagram states the actual percentage of the resulted hydrated binder components. It, also, detects the changes in hydration products due to the presence of glass powder.

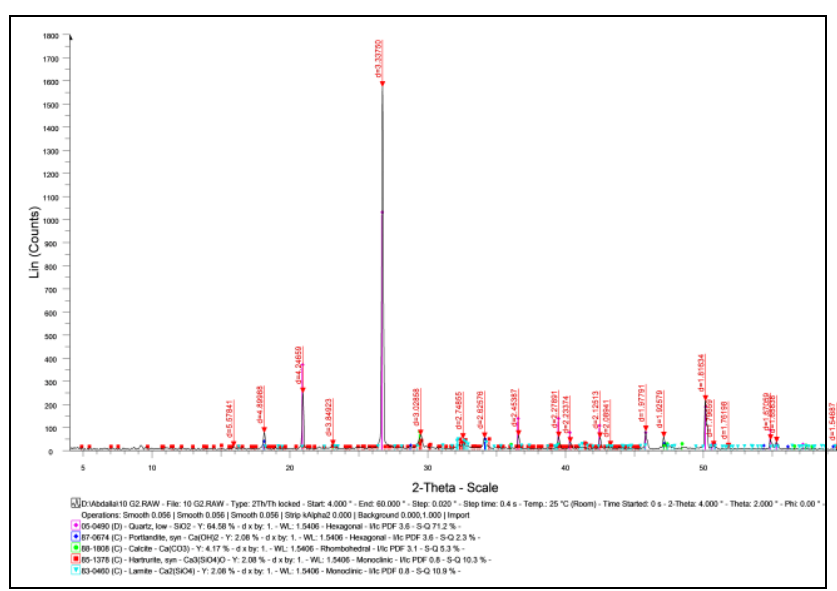

Fig.12. XRD diagram for 5\% GLP replacement by cement weight in mortar

Due to its crystalline nature, calcium hydroxide $\mathrm{Ca}(\mathrm{OH})_{2}$ and calcite $\mathrm{CaCO}_{3}$ can be detected in the XRD diagrams, while amorphous materials such as calcium silicate $\mathrm{Ca}_{2} \mathrm{SiO}_{4}$ cannot be directly detected using this technique, a chemical analysis might be needed. Silica peaks can be clearly detected with high counts which help and influenced the improvement of the compressive strength in cement mortars.

\section{Conclusions}

Based on the results of this experimental investigation under tidal environment, the following conclusions are drawn: 
As the percentage of glass powder increases the workability decreases. The use of super plasticizer was found to be necessary for maintaining workability under restricted water cement ratio criteria [3-9].

Replacement of glass powder in cement will increase the early compressive strength with significant percentage, might reach $20 \%$, after 7 days; however there is no significant increase in compressive strength after 28 days; which means that the glass powder did not react in the cement mortar due to its amorphous nature. It could be better to use it as fine aggregate than as cement replacement. Aging, also, might be a factor to consider in the further investigation [8].

In proportions exceeding $10 \%$, glass powder was found to negative impact the development of compressive strength. It is noticed that in larger quantities, the angular nature of the glass particles reduces available voids in cement mortar. However, the formation of microscopic voids within the concrete matrix might need further investigation [10-11].

5 and $10 \%$ GLP replacement in cement mortar by weight of glass powder in cement increase the flexural strength with significant percentage by a value of $46.9 \%$ after 28 days.

\section{References}

1. B. Jitendra, A. C. Saoji, Int. J. Innov. Comp. Comm., 3 (2015)

2. B. Jitendra, J. Mech. Civil Eng. (IOSR-JMCE), (2014)

3. G. Vijayakumar, H. Vishaliny, D. Govindarajulu, Int. J. Emerg. Tech. Adv. Eng., 3 (2013)

4. S. Raju, P. R. Kumar, Int. J. Innov. Sc., Engineering and Technology, 3 (2014)

5. ASTM C39 / C39M - 18 standard test method for compressive strength of concrete specimens

6. R. Siddique, A. Mehta, Construction and Building Materials, pp. 116-129 (2014)

7. ASTM C78 / C78M - 18 standard test method for flexural strength using simple beam with third-point loading

8. T. Subramani, S.B. Ram, J. Eng. (IOSRJEN), 5 (2015)

9. Sharma, Int. J. Core Eng. \& Manage. (IJCEM), 1 (2015)

10. B. Kumar, M. Ashok, J. Mech. Civil Eng. (IJRDO), 2 (2016)

11. S. Shruthi, S. Chandrakala, G. Narayana, Int. J. Re. Eng. Tech. (IJRET), 4 (2015) 